\title{
Oil prices and financial stress: A volatility spillover analysis
}

\author{
Saban Nazlioglu ${ }^{\mathrm{a}, *}$, Ugur Soytas ${ }^{\mathrm{b}, 1}$, Rangan Gupta ${ }^{\mathrm{c}}$ \\ a Department of Econometrics, Pamukkale University, Denizli, Turkey \\ $\mathrm{b}$ Department of Business Administration, METU, Ankara, Turkey \\ c Department of Economics, University of Pretoria, Pretoria, South Africa
}

H I G H L I G H T S

- Volatility spillover between oil prices and financial stress index is examined.

- Analysis is conducted for sub-periods: pre-crisis, in-crisis, and post-crisis

- Oil prices spill on financial stress before the crisis, but spillover reversed after the crisis.

- Volatility transmission pattern has similar dynamics before and after the crisis.

- Implications for investors and policy makers are discussed.

\begin{abstract}
A B S T R A C T
This paper examines whether there is a volatility transmission between oil prices and financial stress by means of the volatility spillover test. We employ WTI crude oil prices and Cleveland financial stress index for the period 1991-2014 and divide the sample into pre-crisis, in-crisis, and post-crisis periods due to the downward trend in oil price in 2008. The volatility model estimations indicate that oil prices and financial stress index are dominated by longrun volatility. The volatility spillover causality test supports evidence on risk transfer from oil prices to financial stress before the crisis and from financial stress to oil prices after the crisis. The impulse response analysis shows that the volatility transmission pattern has similar dynamics before and after the crisis and is characterized by higher and long-lived effects during the crisis. Our results have implications for both policy makers and investors, and for future work.
\end{abstract}

Keywords:

Oil prices

Financial stress index

Causality

Volatility spillover

\section{Introduction}

It is well established in the literature that oil price shocks have detrimental effect on economic activity in developed and developing countries (i.e. Hamilton, 2011 for US; Cunado and de Gracia, 2003 for 15 European countries; Cunado and de Gracia, 2005 for 6 Asian countries), especially for oil-importers. The evidence on the other hand is not clear-cut for oil exporters (Jimenez-Rodriguez and Sanchez, 2005 for UK and Norway). Although the impact of oil shocks on the macro-economy seems to have weakened through time, Kilian (2008) argues that this is partly due to

\footnotetext{
* Corresponding author. Tel.: +90 258296 2694; fax: +90258 2962626

E-mail addresses: snazlioglu@pau.edu.tr (S. Nazlioglu),

soytas@metu.edu.tr (U. Soytas), rangan.gupta@up.ac.za (R. Gupta).

${ }^{1}$ Fax: +90312 2107962
}

increased demand for industrial output, which offsets the negative impact of an increase in oil price. Rafiq et al. (2009) argue that the negative impact of an increase in oil price is usually found to be higher than the positive impact of a fall in oil prices. It is argued that monetary policy alone cannot account for this asymmetry (see Balke et al., 2002). Transaction costs and financial stress are among the factors that lead to the asymmetric effect. The asymmetric impact of oil shocks on stock returns is also well documented. Aloui et al. (2012), for example, find asymmetric impact of oil shocks on 25 emerging market returns. Park and Ratti (2008) find similar results for US and 13 European economies. They also argue that oil-importers are affected more than oil-exporters.

The dynamic link between oil prices and financial stress can exist through two channels: their impact on economic activity and on investor behavior. A rise in oil prices depresses economic activity, may put pressure on credit markets, and negatively affect 
stock markets and the banking system. In times of high financial stress, economic activity slows down, leading to low energy demand and declining oil prices. Investors see oil markets as alternative investment areas to financial markets. As investors adjust their portfolios with respect to oil price shocks, this will have repercussions on financial asset prices. On the other hand, increased financial stress will also cause investors to change their portfolios and this will have an impact on oil markets. Financial stress also influences economic activity through the bank lending channel via decreasing the amount of available credits and through financial leverage via changes in creditworthiness of borrowing businesses. Even though the linkage between financial stress and economic activity is well-studied (see Illing and Liu, 2006, for a review), the inter-temporal relationship between oil price and financial stress index is not yet well explored.

There are several studies that focus on the equity and commodity market co-movements during crises. A strand of this literature questions the role of speculative component in commodity prices. Killian and Murphy (2014) find evidence on the role of speculative demand on oil shocks in 1979, 1986, and 1990. However, the recent oil price hike during 2003-2008 is due to market fundamentals and not speculation. Büyükșahin and Harris (2011) also support this result. On the other hand, using trader-position level data for non-public traders, Büyükşahin and Robe (2014) show that the association between stock and investable commodity indexes is driven by hedge fund activity, but not other types of traders. They report that during financial turmoil the role of hedge fund activity is weakened. Interestingly TED spread they employ as financial stress signal leads to lower correlation between commodity and equity markets even though hedge fund activity increases. A similar result has also been reported by Büyükşahin et al. (2010), such that during extreme return periods spillovers between commodity and equity markets do not rise significantly. Illing and Liu (2006) point out that the spikes observed in the components of the financial stress index coincide with oil shocks, but to the extent of our knowledge there are no studies that formally test the link between oil price and financial stress index.

This study examines whether there is information transmission between world oil prices and financial stress index. Considering the leading role of the US financial system all over the world, the FSI for US is taken as representative of the global financial stress. ${ }^{2}$ To the extent of our knowledge, this study is the first to explicitly examine spillovers between financial stress and world oil markets by employing the volatility spillover test. To explore the risk transmission, we benefit from the recent developments in time series analysis and use the volatility spillover test of Hafner and Herwartz (2006). We also conduct Toda and Yamamoto (1995) mean causality test and derive the generalized impulse response functions to compare how world oil prices and the FSI respond to short-run temporary shocks. The data set includes daily observations from September 25, 1991 to January 02, 2014 and is divided into three sub-periods due to the downward trend in oil prices in 2008: the pre-oil crisis, the oil crisis, and the post oil crisis (precrisis, crisis, and post-crisis hereafter) periods. The key findings of this study are that (i) oil prices and the financial stress index are dominated by long-run volatility, (ii) there is a volatility transfer from oil prices (financial stress) to financial stress (oil prices) before (after) the crisis, (iii) there is causal linkage from oil prices to financial stress after the crisis and from financial stress to oil prices in the crisis, and finally (iv) the volatility transmission pattern has

\footnotetext{
${ }^{2}$ Dovern and van Roye (2014) show that FSI shock in US transmits rapidly internationally with a persistent negative impact on economic activity. However, a negative shock in US aggregate demand has limited global spillover to financial stress.
}

similar dynamics before and after the crisis and is characterized by higher and long-lived effects during the crisis.

The rest of the paper is organized as follows: The literature review, data description, and causality in variance test is outlined in methodology section (Section 2). In Section 3, we present the descriptive statistics and time series properties of data and interpret the empirical results. Section 4 is devoted to discussion and implications, followed by Section 5 on the concluding remarks.

\section{Methodology}

\subsection{Literature review}

The financial stress index literature is a rapidly developing one. Existing studies either focus on only constructing a financial stress index (FSI) for a country (i.e. Illing and Liu, 2006) or both on constructing and evaluating the link between financial stress and economic activity to examine how well FSI identifies known periods of financial distress (Cevik et al., 2013; Cardarelli et al., 2011; Chau and Deesomsak, 2014; Mallick and Sousa, 2013). There are also a few studies that consider financial stress transmission among countries (Balakrishnan et al., 2009; Park and Mercado Jr., 2014).

Since FSI is a relatively new concept, the literature on impacts of oil prices on macroeconomic and financial variables is a lot broader than the FSI literature. Here we mention only a few recent studies related to the oil price-financial stress literature. ${ }^{3}$ Cunado and de Gracia (2014) examine the link between stock market returns in 12 oil importing European countries and oil prices. They find that in most of these markets returns respond significantly negatively to oil shocks. This negative relationship is confirmed for South Africa by Gupta and Modise (2013). Recognizing that mean spillovers between oil and financial markets may not be covering the entire story, some studies (i.e. Jouini, 2013; Soytas and Oran, 2011) also consider risk transfers. Their findings imply that volatility spillover is another dimension through which financial and oil markets interact. Morana (2013) utilizes a rather comprehensive macro and financial dataset for 31 countries to examine dynamic interaction between oil price and macro-finance variables. The results suggest a large contribution of financial shocks to oil price increases during 2000s while macroeconomic shocks were the main drivers earlier. This result may be largely due to financialization of oil markets. The recent crisis in 2008 is attributed to a macro-finance episode, where macro-shocks carry the burden with financial shocks contributing marginally. The study by Chen et al. (2014) is probably the only article in the literature that examines the link between FSI and oil prices. Using Kansas City FSI, global oil production, global real economic activity, and real oil prices, they find that FSI shocks trigger a significant negative response in real oil prices. Then they consider the impacts of oil, aggregate demand, oil-specific demand, and financial shocks on industrial production, consumer price index, and stock prices in France, Germany, USA, UK, and Japan. Using Killian's (2009) method to distinguish between structural shocks and employing quarterly data for the 1993-2012 period, they show that financial markets play an important role in assessing the impact of oil price shocks on economic activity. Although, they suggest a link between FSI and oil prices, their study does not explicitly consider mean and volatility spillover between FSI and oil prices.

It seems that this newly emerging literature does not yet cover transmissions between FSI and non-financial markets, including oil markets. Financial stress may be contagious and if it is

\footnotetext{
${ }^{3}$ See Gupta and Modise (2013) for a critical review of the literature.
} 
influenced by oil price changes, then oil price shocks will have ripple effects through financial systems of various countries. It would be interesting to examine how oil price shocks influence contagion. However, it is not yet well established whether oil prices and financial stress are linked. Different dimensions of stress in financial markets are captured by FSI. If there is significant mean and volatility spillover from oil prices to financial stress, then investors and policy makers can improve their forecasts of financial distress. How FSI and oil prices respond to changes in one another will shed more light on the complex dynamic relationship between financial markets and oil markets. The economic and financial time series tend to quickly interact with each other and may reflect a volatility transmission structure which can be tested via causality - in-variance tests. It is useful for both investors and policy makers to know whether volatility transmission exists and if it does to identify the direction of the risk spillover between energy and finance markets. It will also be interesting to discern how financial stress responds to volatility shocks in global influential factors such world oil prices.

\subsection{Data sources and description}

We use two variables in this study, a measure of financial stress and oil prices at daily frequency. The decision to carry out the analysis at daily frequency is to better account for the volatilities in these two highly volatile sectors, namely, oil and financial markets. For world oil prices, we use the West Texas Intermediate (WTI) spot crude oil prices, obtained from the FRED database of the St. Louis Federal Reserve Bank. Given that our oil prices are daily, we decided to use the daily financial stress index of the Federal Reserve of Cleveland (CFSI). While there are other financial stress index measures for the US, like the Chicago Fed index, the Kansas City Fed index, and the St. Louis Fed index, none of these indexes are available at daily frequency. Furthermore, due to its comprehensive coverage of dimensions through which financial stress can arise, CFSI is a better representative of stress in financial markets than indexes based on single markets, such as VIX. The purpose of CFSI is to continuously monitor distress signals in the U.S. financial system. Continuous monitoring gives policy makers the ability to detect the building up of stress. Financial stress can quickly be amplified when more than one market is experiencing it, and hence, early detection is of paramount importance. The CFSI considers 6 major financial markets: credit, equity, foreign exchange, funding, real estate, and securitization. In order to capture different dimensions of financial stress in these markets, CFSI uses 16 measures. These measures are: covered interest spread, corporate bond spread, liquidity spread, commercial paper and Treasury-bill spread, Treasury yield curve spread, stock market crashes, weighted dollar crashes, financial beta, bank bond spread, interbank liquidity spread, interbank cost of borrowing, commercial real estate, residential real estate, residential MBS, commercial MBS and asset-backed securities. ${ }^{4}$ Summated scales are formed to represent securitization, credit, interbank, real estate, equity, and foreign exchange markets. Then a principle component analysis on the six scales is used to arrive at the single CFSI.

The data set includes daily observations from September 25, 1991 to January 02, 2014 and as discussed in the introduction it is divided into three sub-periods: the pre-crisis period from September 25, 1991 to December 31, 2007, the crisis period from January 01, 2008 to December 31, 2008, the post-crisis period from January 01, 2009 to January 02, 2014. The starting date of the sample is constrained by availability of CFSI (even though the WTI starts earlier), and all available data since the start of this study is included.

By comparing volatility spillovers during the pre-crisis, the incrisis and the post-crisis, the results should clearly indicate how spillover mechanism between oil prices and financial stress stands the test of time. The choice of the sub-periods is based on the downward trend in oil prices within the year 2008. As shown in Mollick and Assefa (2013) and Turhan et al. (2013) oil-stock price and oil-exchange rate link is severed in 2008. Their results suggest when oil prices are used, separate analyses are necessary before, at and after 2008. Mollick and Assefa (2013) find changing correlations between stock markets and oil prices for three sub samples. The insignificant correlations pre 2008 and within January 2008June 2009 period, are followed by positive and significant correlations after the crisis. This suggests that the dynamic inter-temporal relationship between financial stress and oil prices may be subject to structural change due to the 2008 crisis. Turhan et al. (2013) find similar results for oil prices and emerging market exchange rates. In the light of the literature, we therefore question the impact of the 2008 crisis on the financial stress and oil price link and thus the data is divided into three sub-periods: the precrisis period from September 25, 1991 to December 31, 2007, the crisis period from January 01, 2008 to December 31, 2008; and the post-crisis period from January 01, 2009 to January 02, 2014.

Fig. 1 illustrates movements of oil prices and CFSI. The FSI has four grades such that Grade 1 denotes a low stress period if CFSI $<-0.733$, Grade 2 is a normal stress period if $-0.733 \geq$ CFSI $<0.544$, Grade 3 is a moderate stress period if $0.544 \geq$ CFSI $<$ 1.82 , and finally Grade 4 is a significant stress period if CFSI $\geq 1.82$. At first glance, there is a normal stress period from 1991 to 1998 in CFSI. Within the same period, oil prices appear to have a stable pattern. During the 1998-2007 periods, CFSI alternates between moderate and normal stress periods and shows a volatile pattern which is matched with an upward trend in oil prices. After the financial turmoil in 2008, even though fluctuations in CFSI range between normal and stress grades, the index appears more volatile compared to the oil price. In summary, it can be concluded from Fig. 1, that the two series have tended to move more closely during and after the crisis relative to the pre-crisis period. It seems that the link between CFSI and world oil prices have changed through time. This, in turn, motivated us to concentrate on the sub-sample analysis.

\subsection{Causality in variance test}

This study employs Lagrange multiplier (LM) based causalityin-variance test by Hafner and Herwartz (2006) to assess the existence and direction of dynamic volatility transmission between oil prices and financial stress. The causality concept by Granger (1996) implies that a variable causes the other variable if the former variable has predictive power for forecasting the latter

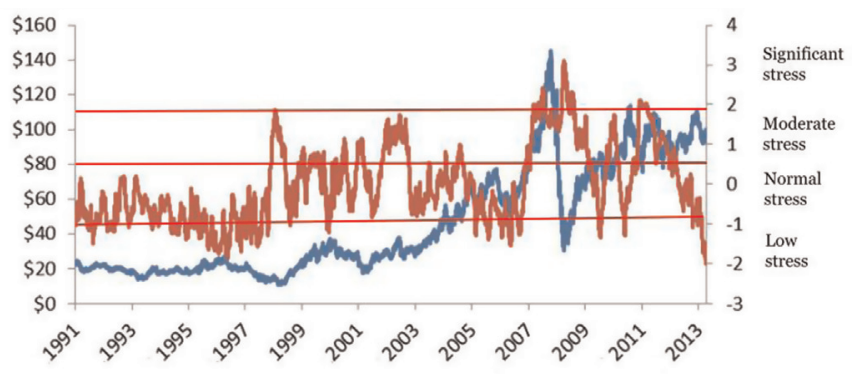

${ }^{4}$ Further details are available at: https://www.clevelandfed.org/research/data/ financial_stress_index/about.cfm.

Fig. 1. Dynamics of oil prices and financial stress index. 
variable. Earlier Granger causality-in-variance tests (Cheung and $\mathrm{Ng}$, 1996; Hong, 2001) rely on the cross-correlation functions (CCF) of the standardized residuals from univariate $\mathrm{GARCH}^{5}$ equations of any two series. However, this type of a portmanteau test exhibits "significant oversizing in small samples when the volatility processes are leptokurtic" (Hafner and Herwartz, 2006). Furthermore, the CCF based approaches require an arbitrary selection of lead and lag orders and results are sensitive to selected orders. The LM based Granger causality in variance test of Hafner and Herwartz (2006) does not have the shortcomings of earlier tests. Furthermore, they show that the LM approach is more robust and the gain from this test increases with the sample size.

To test the null hypothesis of no volatility spillover, the procedure is followed as

$\left.\varepsilon_{i t}=\xi_{i t} \sqrt{\sigma_{i t}^{2}\left(1+z_{j}^{\prime} \pi\right.}\right), \quad z_{j t}=\left(\varepsilon_{j t-1}^{2}, \sigma_{j t-1}^{2}\right)^{\prime}$

where $\xi_{i t}$ and $\sigma_{i t}^{2}$ are respectively the standardized residuals and the conditional variance (volatility) for the series $i ; \varepsilon_{j t-1}^{2}$ and $\sigma_{j t-1}^{2}$ are respectively the squared disturbance term and the conditional variance for the series $j$. The null hypothesis $H_{0}: \pi=0$ is of noncausality and the alternative hypothesis $H_{1}: \pi \neq 0$ states that causality exists. The Gaussian $\log$-likelihood function of $\varepsilon_{i t}$ is used to get the score as $x_{i t}\left(\xi_{i t}^{2}-1\right) / 2$ where $x_{i t}$ are the derivatives of the likelihood function in terms of GARCH parameters. The following test statistic is then used for the volatility spillover test:

$\lambda_{L M}=\frac{1}{4 T}\left(\sum_{t=1}^{T}\left(\xi_{i t}^{2}-1\right) z_{j t}^{\prime}\right) V\left(\theta_{i}\right)^{-1}\left(\sum_{t=1}^{T}\left(\xi_{i t}^{2}-1\right) z_{j t}\right)$

where

$V\left(\theta_{i}\right)=\frac{\kappa}{4 T}\left(\sum_{t=1}^{T} z_{j t} z^{\prime}{ }_{j t}-\sum_{t=1}^{T} z_{j t} x_{i t}^{\prime}\left(\sum_{t=1}^{T} x_{i t} x_{i t}^{\prime}\right)^{-1} \sum_{t=1}^{T} x_{i t} z^{\prime}{ }_{j t}\right)$,

$\kappa=\frac{1}{T} \sum_{t=1}^{T}\left(\xi_{i t}^{2}-1\right)^{2}$

The asymptotic distribution of the test statistic in Eq. (2) depends on how many indicators of misspecification there are in $z_{j t}$. Since in $\lambda_{L M}$ equation there are two such indicators, the statistic has a chi-square distribution with two degrees of freedom asymptotically. Rejecting the null hypothesis implies volatility spillover from series $j$ to series $i$. Similar steps enable us to test causality from $i$ to $j$.

\section{Empirical results}

\subsection{Descriptive statistics and time series properties}

Before proceeding to data characteristics as well as econometric analysis, we first investigate the unit root properties of the oil prices and FSI by applying a battery of unit root tests. The results reported in Table 1 for the unit root tests developed by Dickey and Fuller (1979) (ADF), Elliott et al. (1996) (DF-GLS), and Kwiatkowski et al. (1992) (KPSS). It is worthwhile to note here that the null hypothesis of the KPSS test is stationarity and differs from the null hypothesis of a unit root for ADF and DF-GLS tests. All the unit root tests indicate that oil prices are characterized by a unit

${ }^{5}$ Since the focus of this paper is to investigate volatility spillover by the means of causality-in-variance approach, we do not outline ARCH and GARCH models in order to save space. We kindly refer an interested reader to Engle (1982), Bollerslev (1986), and Bollerslev et al. (1992) for a detailed explanation of the volatility models. root process, implying that the shocks are permanent and not corrected over time. For the FSI, even though the ADF and DF-GLS tests support evidence on stationary process in the pre-crisis period, this mean reverting process is not supported by the KPSS test. The three tests show that the FSI is non-stationary in the post-crisis period. In the crisis period, the DF-GLS test implies a stationary behavior of the FSI while other two tests are in contrast.

The ADF, DF-GLS and KPSS tests do not take into account possible structural break(s) in series. Given that the period under study is very likely to contain such breaks, it would be more relevant to apply unit root tests robust to breaks over the full sample. ${ }^{6}$ In that respect, we employ a new augmented DickeyFuller-type test for unit roots which accounts for two structural breaks recently developed by Narayan and Pop (2010).The results from the unit root test with structural shifts in Table 1 are similar to those from ADF and DF-GLS tests. The Narayan and Pop's test shows that the null hypothesis of unit root process cannot be rejected for oil prices, but is rejected for the FSI. Accordingly, the structural shifts do not seem to effect the unit root behavior of oil prices and the FSI.

At the bottom of Table 1, we report summary statistics of oil prices and CFSI for different samples in order to examine to what extent the descriptive statistics of the oil prices and the FSI differ across these sub periods. Summary statistics are calculated on stationary series (first logged difference of oil prices and first difference of financial stress index). It seems that oil prices have highest mean and standard deviation during the crisis period. The standard deviations of oil prices - a simple measurement for volatility - is higher in the post-crisis period compared to that of the pre-crisis period. This is due to the fact that oil price moves between 23 and 99 US dollars in the pre-crisis period, while it fluctuates within a shorter band, namely 88 and 113 US dollars, in the post-crisis period. As it is well known, skewness is a simple measure of asymmetry and kurtosis is a measurement for peaked or flatted distribution relative to a normal distribution. We observe that oil price has positive skewness and is right tailed in the crisis period; although it has negative skewness and hence left tailed in both the pre- and post-crisis periods. This stylized fact is also supported by the Jarque-Bera statistic which rejects the null hypothesis of normality.

Financial stress index has positive and the greatest mean in the in-crisis period, which means that there is a significant or higher stress. It has positive mean in the pre-crisis and negative mean in the post-crisis. As illustrated in Fig. 1, these features provide that the pre-crisis period is characterized as a normal stress period while moderate stress levels are observed in the post-crisis period. Financial stress index has smallest standard deviation during the crisis-period compared to the pre- and post-crisis periods. Skewness shows that financial stress index is right tailed in the crisis and post-crisis periods; it has left tail in the pre-crisis period. Kurtosis indicates that financial stress is less peaked during the crisis compared to the pre- and post-crisis periods. The JarqueBera statistic also shows non-normal behavior of financial stress.

The different data characteristics apparent in the descriptive statistics for different periods lead to the question of whether the correlations between oil prices and financial stress vary across these sub-periods as well. At first glance, correlation appears stronger in the post-crisis periods than those in the pre- and incrisis period. However, the positive correlation in the post-crisis period turns back to negative following the financial crisis. This means that as financial stress goes from moderate level to normal level, oil prices go up. This reversed relationship becomes more apparent after 2011 according to Fig. 1. It is important to note that

\footnotetext{
${ }^{6}$ We are grateful to anonymous referee for pointing out this comment.
} 
Table 1

Data properties.

\begin{tabular}{|c|c|c|c|c|c|c|c|c|}
\hline & \multicolumn{4}{|l|}{ Oil prices } & \multicolumn{4}{|c|}{ Financial stress index } \\
\hline & $\begin{array}{l}\text { Full sample } \\
25 / 10 / 1991 \\
02 / 01 / 2014\end{array}$ & $\begin{array}{l}\text { Pre-crisis } \\
25 / 10 / 1991 \\
31 / 12 / 2007\end{array}$ & $\begin{array}{l}\text { In-crisis } \\
01 / 01 / 2008 \\
31 / 12 / 2008\end{array}$ & $\begin{array}{l}\text { Post-crisis } \\
01 / 01 / 2009 \\
02 / 01 / 2014\end{array}$ & $\begin{array}{l}\text { Full sample } \\
25 / 10 / 1991 \\
02 / 01 / 2014\end{array}$ & $\begin{array}{l}\text { Pre-crisis } \\
25 / 10 / 1991 \\
31 / 12 / 2007\end{array}$ & $\begin{array}{l}\text { In-crisis } \\
01 / 01 / 2008 \\
31 / 12 / 2008\end{array}$ & $\begin{array}{l}\text { Post-crisis } \\
01 / 01 / 2009 \\
02 / 01 / 2014\end{array}$ \\
\hline $\begin{array}{l}\text { Panel A: Unit ro } \\
\text { ADF } \\
\text { DF-GLS } \\
\text { KPSS } \\
\text { NP-with breaks }\end{array}$ & $\begin{array}{l}-1.034 \\
-0.320 \\
8.120^{\text {*klk* }} \\
-3.680\end{array}$ & $\begin{array}{c}-0.370 \\
0.044 \\
5.928^{* * * *}\end{array}$ & $\begin{array}{l}0.088 \\
0.371 \\
0.896^{* * * *}\end{array}$ & $\begin{array}{l}-2.598^{*} \\
-0.210 \\
2.812^{\text {****k }}\end{array}$ & $\begin{array}{r}-4.143^{* * * *} \\
-2.970^{* * * * *} \\
2.585^{* * * *} \\
-5.958^{* * * *}\end{array}$ & $\begin{array}{r}-4.349^{* * * * *} \\
-2.949^{* * * *} \\
1.815^{\text {**** }}\end{array}$ & $\begin{array}{l}-0.869 \\
-1.728^{* * *} \\
0.254\end{array}$ & $\begin{array}{r}-2.262 \\
0.025 \\
0.991^{* * * *}\end{array}$ \\
\hline \multicolumn{9}{|c|}{ Panel B: Descriptive Stats. } \\
\hline Mean & 0.013 & 0.018 & -0.218 & 0.038 & -0.00017 & 0.000658 & 0.005325 & -0.003987 \\
\hline Median & 0.020 & 0.020 & -0.160 & 0.090 & -0.00036 & 0.000932 & 0.002577 & -0.003922 \\
\hline Maximum & 18.560 & 4.360 & 18.560 & 7.620 & 0.416 & 0.416066 & 0.210958 & 0.371653 \\
\hline Minimum & -14.760 & -6.520 & -14.760 & -8.900 & -0.358 & -0.358619 & -0.100571 & -0.239765 \\
\hline Std. Dev. & 1.222 & 0.758 & 3.326 & 1.595 & 0.060 & 0.062450 & 0.044449 & 0.056335 \\
\hline Skewness & 0.067 & -0.190 & 0.368 & -0.150 & 0.030 & -0.015441 & 0.926371 & 0.134723 \\
\hline Kurtosis & 23.188 & 8.863 & 7.794 & 5.033 & 7.624 & 7.764923 & 5.922380 & 6.417821 \\
\hline Jarque-Bera & 95125.980 & 5880.296 & 247.079 & 221.9077 & 4990.845 & 3866.549 & 125.7160 & 617.0904 \\
\hline Probability & 0.000 & 0.000 & 0.000 & 0.000 & 0.000 & 0.000 & 0.000 & 0.000 \\
\hline Observations & 5601 & 4087 & 252 & 1260 & 5601 & 4087 & 252 & 1260 \\
\hline Correlation & -0.0282 & 0.032 & -0.040 & -0.144 & & & & \\
\hline
\end{tabular}

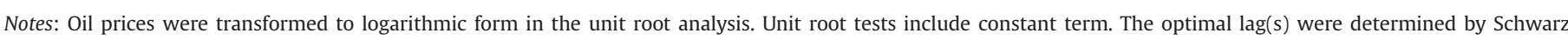
information criterion. Barlett kernel for spectral estimation and Newey-West method for bandwith were used for KPSS test.

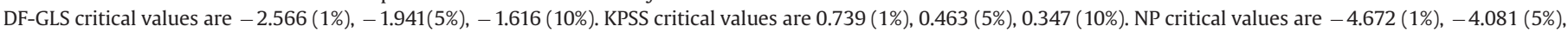
$-3.772(10 \%)$.*****, and * indicate respectively statistical significance at the 1,5 , and 10 percent levels.

Table 2

Results for variance equations.

\begin{tabular}{|c|c|c|c|c|c|c|c|c|}
\hline \multirow[t]{2}{*}{ Oil price } & \multicolumn{2}{|l|}{$\begin{array}{l}\text { Full sample } \\
25 / 10 / 1991 \\
02 / 01 / 2014\end{array}$} & \multicolumn{2}{|l|}{$\begin{array}{l}\text { Pre-crisis } \\
25 / 10 / 1991 \\
31 / 12 / 2007\end{array}$} & \multicolumn{2}{|l|}{$\begin{array}{l}\text { In-crisis } \\
01 / 01 / 2008 \\
31 / 12 / 2008\end{array}$} & \multicolumn{2}{|l|}{$\begin{array}{l}\text { Post-crisis } \\
01 / 01 / 2009 \\
02 / 01 / 2014\end{array}$} \\
\hline & Coeff. & $p$-Value & Coeff. & $p$-Value & Coeff. & $p$-Value & Coeff. & $p$-Value \\
\hline$\omega$ & $4.04 \mathrm{E}-06$ & 0.000 & $3.81 \mathrm{E}-06$ & 0.000 & $1.64 \mathrm{E}-05$ & 0.376 & $5.25 \mathrm{E}-06$ & 0.001 \\
\hline$\alpha$ & 0.058 & 0.000 & 0.050 & 0.000 & 0.154 & 0.000 & 0.051 & 0.000 \\
\hline$\beta$ & 0.935 & 0.000 & 0.944 & 0.000 & 0.855 & 0.000 & 0.931 & 0.000 \\
\hline \multicolumn{9}{|c|}{ Financial stress index } \\
\hline$\omega$ & $7.96 \mathrm{E}-05$ & 0.000 & 0.000 & 0.000 & $3.93 \mathrm{E}-05$ & 0.193 & $4.51 \mathrm{E}-05$ & 0.000 \\
\hline$\alpha$ & 0.086 & 0.000 & 0.094 & 0.000 & 0.071 & 0.010 & 0.089 & 0.000 \\
\hline$\beta$ & 0.891 & 0.000 & 0.873 & 0.000 & 0.910 & 0.000 & 0.901 & 0.000 \\
\hline
\end{tabular}

Note: The variance equation is $\sigma_{t}^{2}=\omega+\alpha u_{t-1}^{2}+\beta \sigma_{t-1}^{2}$ in which $\alpha$ is the ARCH effect and $\beta$ is the GARCH effect.

Table 3

Result for causality-in-variance test.

\begin{tabular}{llllll}
\hline & \multicolumn{2}{l}{ Spillover from oil prices to FSI } & & \multicolumn{2}{l}{ Spillover from FSI to oil prices } \\
\cline { 2 - 3 } \cline { 5 - 6 } \cline { 5 - 6 } & LM-stat & $p$-Value & & LM-stat & $p$-Value \\
\hline Full sample & $7.310^{* * *}$ & 0.025 & 1.722 & 0.422 \\
Pre-crisis & $9.489^{*}$ & 0.086 & & 0.900 & 0.637 \\
In-crisis & 2.041 & 0.360 & & 3.800 & 0.149 \\
Post-crisis & 1.678 & 0.431 & & $9.502^{* * * *}$ & 0.008 \\
\hline
\end{tabular}

$* * *, * *$, and $*$ indicate respectively statistical significance at the 1,5 , and 10 percent levels.

linear correlation coefficient between two variables does not necessarily imply causation. While correlation coefficient is used to see linear dependence between two variables, the causality concept is used to investigate whether variable(s) of interest provides a predictive power for other variable. It is therefore required to employ advanced econometric tools in determining causal linkages between the oil prices and the financial stress index.
Table 4

Result for Toda-Yamamoto causality test.

\begin{tabular}{llllll}
\hline & \multicolumn{2}{l}{ Causality from oil prices to FSI } & & \multicolumn{2}{l}{ Causality from FSI to oil prices } \\
\cline { 2 - 3 } \cline { 5 - 6 } \cline { 5 - 6 } & LM-stat & $p$-Value & & LM-stat & $p$-Value \\
\hline Full sample & 11.035 & 0.273 & 23.118 & 0.059 \\
Pre-crisis & 11.130 & 0.156 & 19.170 & 0.238 \\
In-crisis & 10.934 & 0.280 & & $27.110^{* * * * *}$ & 0.001 \\
Post-crisis & $16.713^{*}$ & 0.053 & 7.532 & 0.581
\end{tabular}

$* * * * * *$, and $*$ indicate respectively statistical significance at the 1,5 , and 10 percent levels.

\subsection{Variance spillover test results}

The Lagrange multiplier test described in Eq. (2) requires estimating the univariate GARCH $(1,1)$ models. $^{7}$ The variance equation

\footnotetext{
${ }^{7}$ It is worthwhile noting that the GARCH model assumes a stationary series.
} 
Response of FSI volatility to oil price volatility
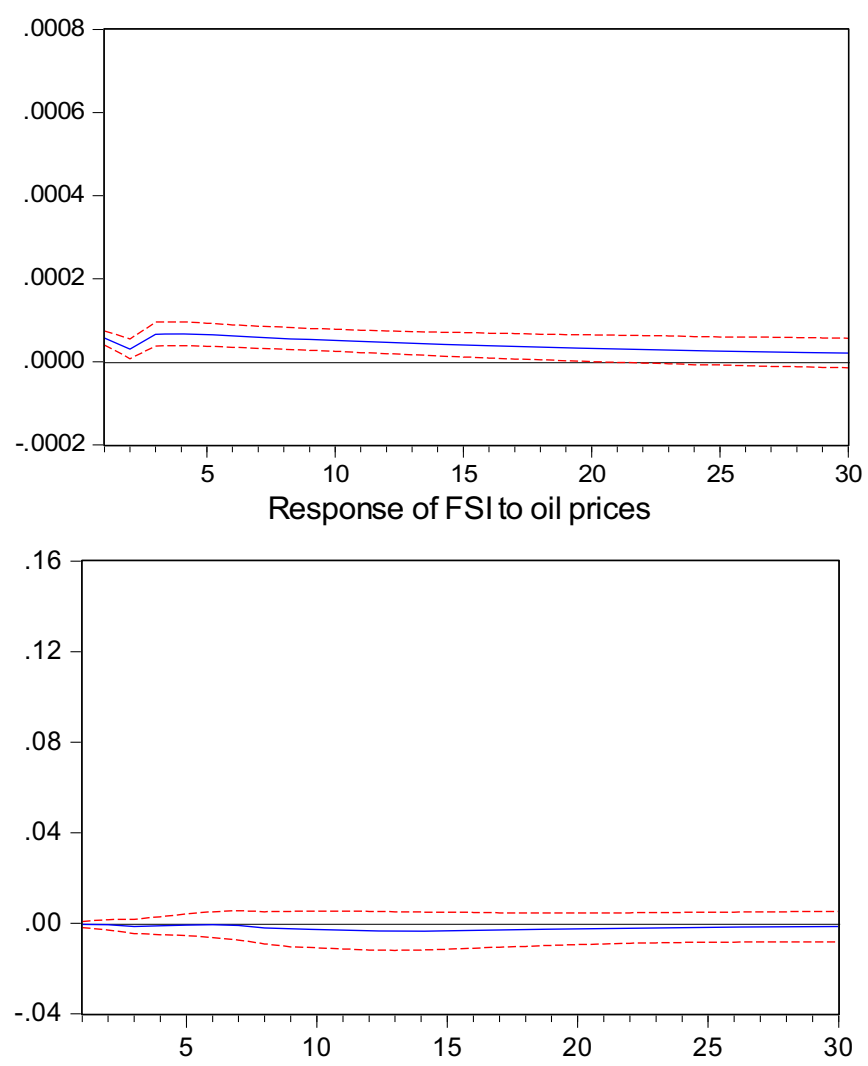

Response of oil price volatility to FSI volatility
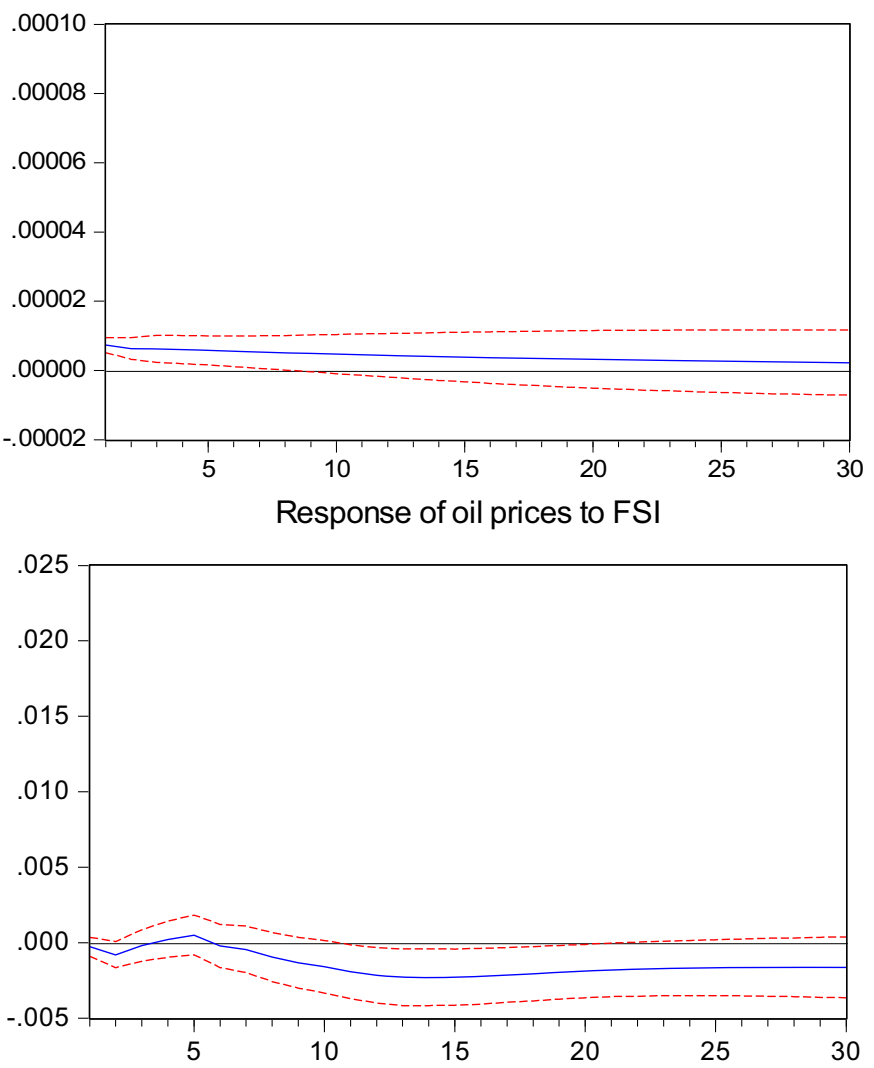

Fig. 2. Impulse-response functions for the full sample.

in $\operatorname{GARCH}(1,1)$ model is described as

$\sigma_{t}^{2}=\omega+\alpha \varepsilon_{t-1}^{2}+\beta \sigma_{t-1}^{2}+u_{t}$

In this specification, it is assumed the stability conditions (intercept $\omega>0$, the ARCH parameter $\alpha \geq 0$, the GARCH parameter $\beta \geq 0$, and $\alpha+\beta<1$ ) of the GARCH model are satisfied. In Table 2, we report the results from the GARCH estimations. Before proceeding to inferences from the estimation, one needs to check whether the stability conditions are hold. The results support the validity of the stability conditions for the estimated GARCH models except for the oil price model during the in-crisis period. This is probably due to the turbulence and high uncertainty experienced in oil markets during this period. Therefore, inferences from the GARCH model of oil prices in the crisis period should be used with caution and we derive our interpretations being aware of this limitation.

The positive coefficients in the variance equations signify the importance of the conditional variance (volatility) process of the variables. The volatility processes of the oil prices and financial stress appear to have a similar structure. The volatility structure slightly differs in the crisis period relative to the pre- and the postcrisis periods. More specifically, the ARCH parameter of the oil price equation shows a dramatic increase during the financial turmoil of 2008 (i.e., the in-crisis period). On the other hand, the GARCH parameter is slightly smaller in the crisis period than in the pre- and post-crisis period. The degree of persistence $(\alpha+\beta)$ in the pre- and post-crisis periods imply that there is a fair amount of persistence of the impact of the volatility shocks on oil returns.

(footnote continued)

The unit root analysis in Table 1 shows that the series are not stationary in the level form; hence we use first differences of CFSI and of log-oil prices.
The picture for financial stress index seems in contrast with the volatility behavior of oil prices. Although the ARCH effect in financial stress is smaller in the crisis period than that in the preand post-crisis, the GARCH parameter is getting larger during the crisis.

The persistency of the long-run volatility leads us to question whether there is a volatility transfer between oil prices and financial stress in the long run. The results from volatility spillover analysis are illustrated in Table 3. Before the crisis (in the pre-crisis period) the null hypothesis of no volatility spillover from oil prices to financial stress index is rejected; in contrast, the volatility transfer does not appear from financial stress index to oil prices. During the crisis (in the crisis period), the null hypothesis cannot be rejected and thereby there is risk transfer neither from oil prices to financial stress index nor from financial stress index to oil prices. This indicates neutrality between energy and financial markets during the crisis. This is in line with Turhan et al. (2013) findings for exchange rates and oil prices. Although this seems to be contradictory to the existence of a contagion effect, ${ }^{8}$ decoupling of commodity and equity markets during crisis is also documented by Büyükşahin et al. (2010) and Büyükş̧ahin and Robe (2014). The turmoil in the oil markets may have severed the link between oil price and FSI as investors try to adjust their expectations to increased uncertainty and change their positions. After the crisis (in the post-crisis period), the null hypothesis of no volatility transfer from oil prices to financial stress cannot be rejected. However, we reject the hypothesis of no spillover from financial stress to oil prices. Thereby, it is clear that the direction of volatility spillover between oil and financial markets is reversed after the crisis. Before the crisis, financial markets were led by risk in oil markets;

\footnotetext{
${ }^{8}$ We thank an anonymous referee for pointing this out.
} 
Response of FSI volatility to oil price volatility

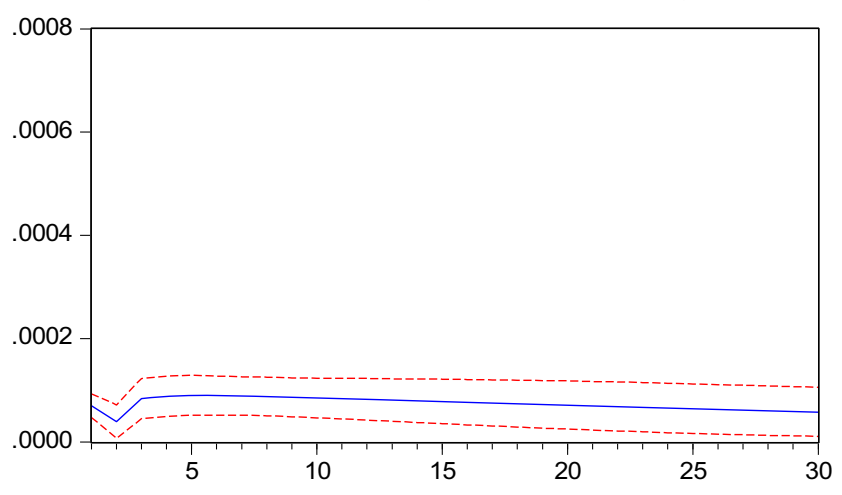

Response of FSI to oil prices

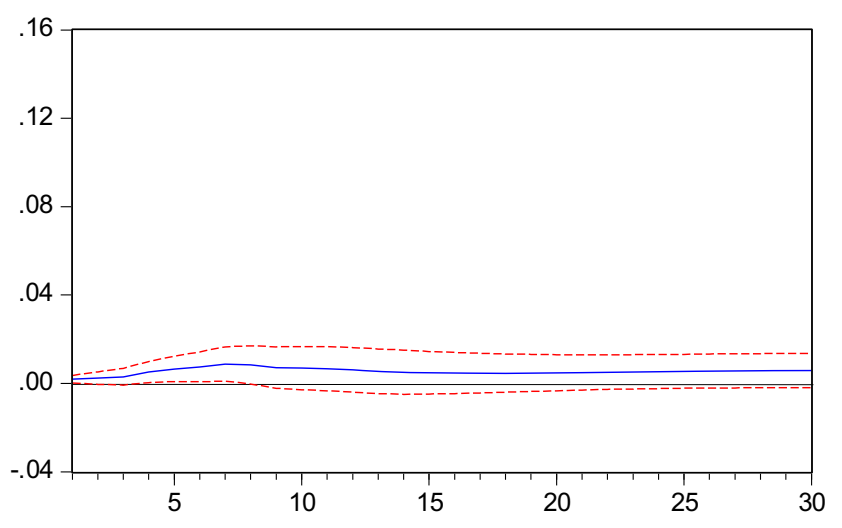

Response of oil price volatility to FSI volatility

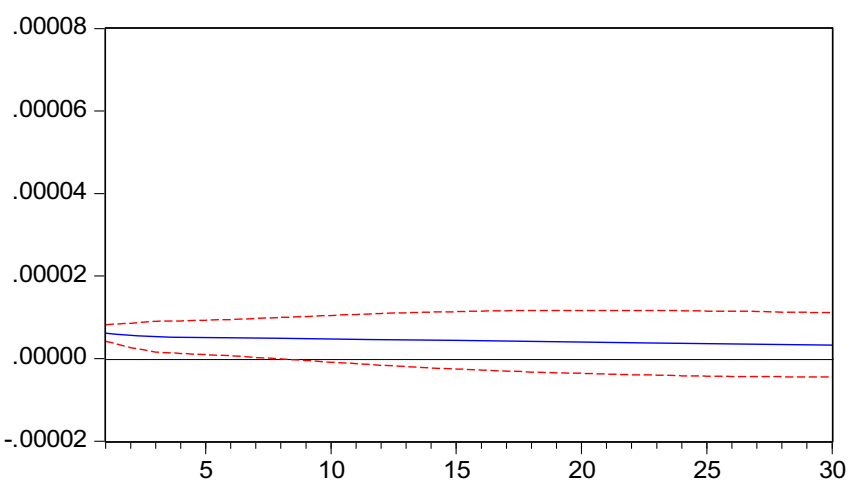

Response of oil prices to FSI

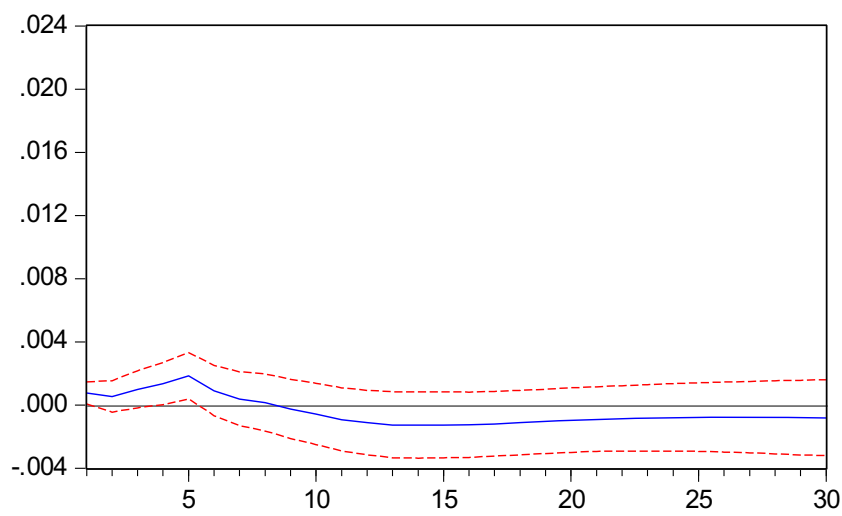

Fig. 3. Impulse-response functions for the pre-crisis period.

however, after the crisis financial markets seem to become dominant. Hedging and portfolio formation decisions of investors in the financial asset markets started influencing the oil price volatility probably due to increased financialization of the oil market.

The causality-in-variance test enables us to examine the nature of volatility transfers between two time series. Risk perceptions can change rapidly and investors can adjust their hedging strategies in response to changes in return volatilities. However, the price adjustment process can be thought of as a gradual process that changes the level of long run equilibrium prices. This gradual change in equilibrium prices is more relevant for long run portfolio diversification strategies. This implies that there may be differences in causal linkages between variances and the levels of oil price-financial stress index nexus. The causality-in-variance tests cannot capture the nature of long run spillovers between means.

\subsection{Mean spillover test results}

The traditional Granger causality methods are the most commonly used tools in examining the mean spillover between time series variables. To determine the direction of causality (mean spillover) between oil price and financial stress index, we employ the Granger causality test proposed by Toda and Yamamoto (1995). This method does not require testing for co-integration and is robust to the unit root and cointegration properties of the series. Besides, there is no need to transform the original series in order to work with their stationary forms. This enables us to avoid any information loss due to differencing. Since the variables are employed in their levels, one can refer to the Toda-Yamamoto approach as a long-run causality test (Awokuse, 2003; Nazlioglu and
Soytas, 2011). In the Toda-Yamamoto approach, VAR ( $p+d m a x)$ model is first estimated in which $p$ is the optimal lag length(s) and dmax is the maximum integration degree of the variables. ${ }^{9}$ Then Wald statistic for the null of non-causality in Granger sense is obtained by imposing zero restriction on first $p$ lags.

The results from the Toda-Yamamoto causality analysis are presented in Table 4. Neither the oil prices nor financial stress Granger causes each other before the crisis. However, the causality-in-variance analysis supports information transmission from energy markets to financial markets. During the crisis, the results from Toda-Yamamoto approach again differ from those of the volatility spillover test. As indicated, volatility spillover analysis shows neutrality between oil price and financial stress in the crisis period. In contrast, the TY analysis provides evidence of information flow from financial stress to oil prices. Hence, an equilibrium link seems to be emerging between the two series. The dis-similarity between volatility spillover and causality analyses is also apparent in the post-crisis period. Even though, the causality-invariance test shows variance transfer from financial stress to oil prices, the Toda-Yamamoto causality test indicates exactly the opposite and hence supports existence of information transmission from oil prices to financial stress.

\subsection{Generalized impulse response results}

To distinguish how the variables of interest respond to shortrun temporary shocks, we can utilize the impulse-response

\footnotetext{
${ }^{9}$ The lag lengths which satisfy the no-serial correlation assumption and the stability condition properties of VAR models selected by general-to-specific approach. The unit root tests in Table 1 indicated that dmax is found to be one.
} 
Response of FSI to oil prices volatility
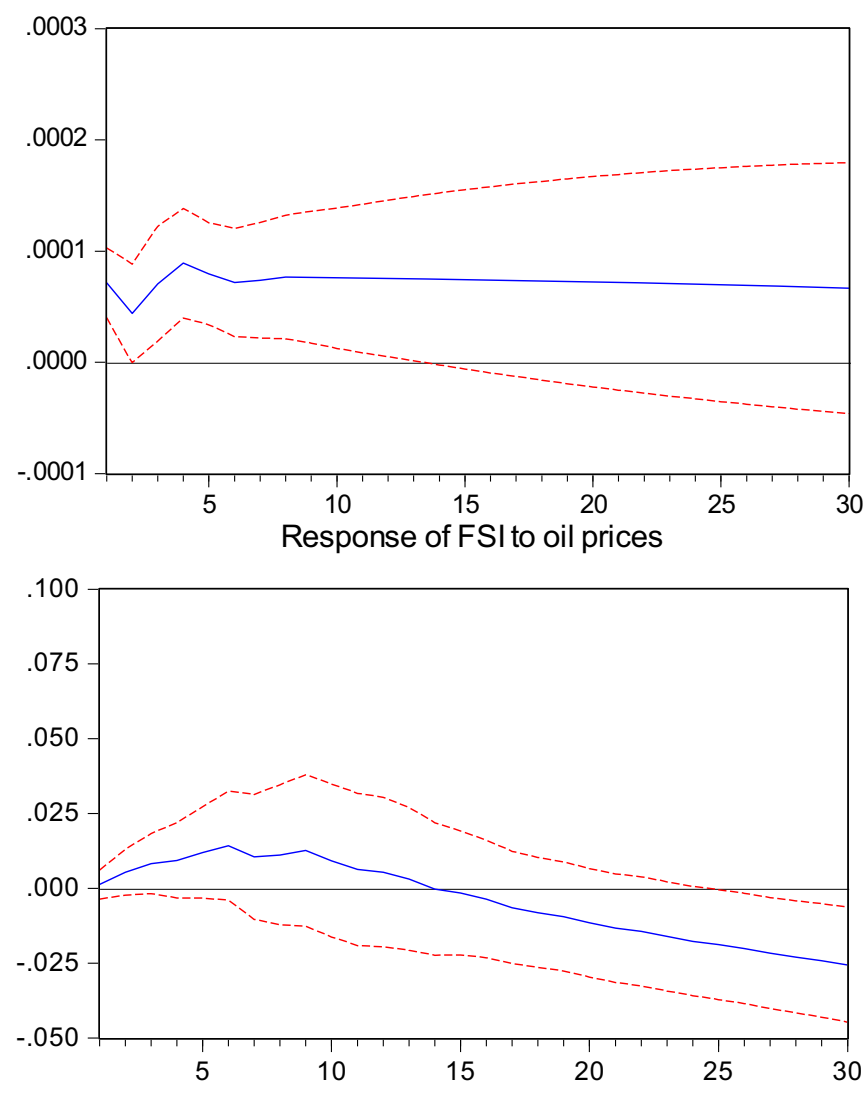

Response of oil prices volatility to FSI volatility
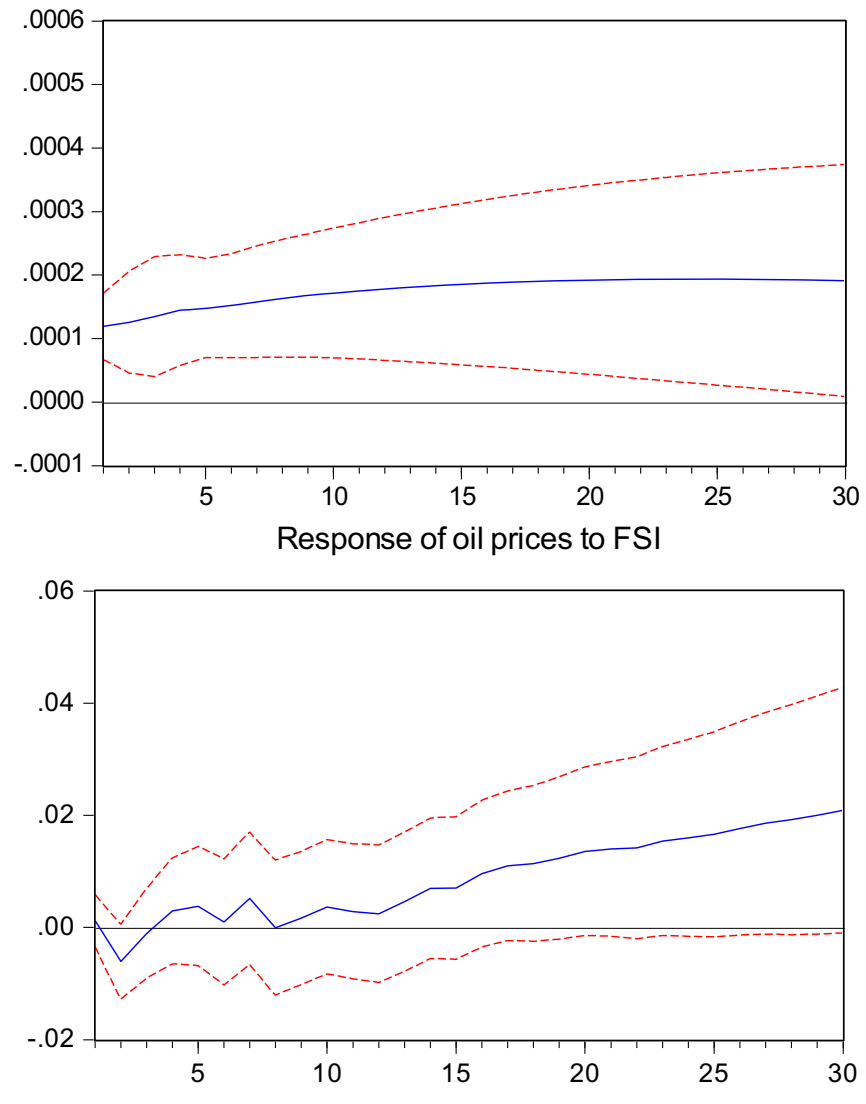

Fig. 4. Impulse-response functions for the in-crisis period.

functions. To this end, we benefit from the flexibility of the generalized impulse-response approach advocated by Koop et al. (1996), and Pesaran and Shin (1998). The generalized functions are superior to the traditional approach because their results are robust to the order in which variables enter the system. The generalized impulse responses are not subject to the orthogonality critique due to Cholesky decomposition.

It is worthwhile to note here that the differences in causality linkages for volatility and level of oil prices and financial stress index relations motivated us to look at the impulse-response functions for volatility and levels. The generalized impulse-response functions of the variance (volatility) series are obtained for one standard deviation shock in the variance those are obtained from the GARCH $(1,1)$ estimations. The generalized impulse-response functions are based on the VAR models (estimated for the Toda-Yamamoto causality test) for one standard deviation shock in oil prices and financial stress index. It is also worth noting here that the impulse-response function for variance shocks in the crisis period should be viewed with caution because oil prices do not satisfy the stability conditions for the GARCH model in this period.

The results from impulse-response analysis are illustrated through Figs. 2-5. As in the causality analysis, interesting findings are in order. First, although all the impulse-response functions for the volatility are initially significant for all the periods, the functions for level series are significant only in the post-crisis period. Second, although the impulse-response functions for the variance show similar patterns in the pre- and post-crisis period, they show different patterns in the crisis period. Before and after the crisis the impulse-response functions are initially positive and shortlived; but the initial positive responses are getting larger and more persistent (long-lived) in the crisis. This finding first shows that the behavior of volatility transmission between energy and financial markets tends to change considerably during the crisis period. It also implies that risk perceptions transfer more quickly between energy and financial markets during the crisis. Finally, we observe the variance and level shocks in the post-crisis period works in different directions. Specifically, while variance shocks lead to positive and quickly dying responses, the effects of the level shocks seems negative and more persistent.

Overall, our results show that FSI and oil prices are linked. Furthermore, after the crisis the stress built up in financial asset markets seem to spillover to oil market. This implies that as financialization of commodity markets become deeper, the information transmission between FSI and oil prices will become more significant. Specifically, our Granger causality in mean results suggest that the level of FSI can be predicted better by including oil price in the forecasts. For risk transmission though, the reverse is true. The Granger causality in variance result suggests that oil price volatility forecasts can be improved by taking FSI volatility into account.

\section{Discussion}

The ARCH and GARCH parameters show different volatility process. While the ARCH parameter implies the short-run volatility, the GARCH parameters indicates persistent volatility. The results at first glance imply that the volatility processes of oil prices and financial stress index work against each other. The crisis leads to an increase in the short-run volatility and a decrease in the long-run volatility of oil prices. In contrast, in the crisis period financial stress tends to have a smaller short-run volatility and a higher long-run volatility. Nevertheless, it also appears that oil 
Response of FSI volatility to oil prices volatility

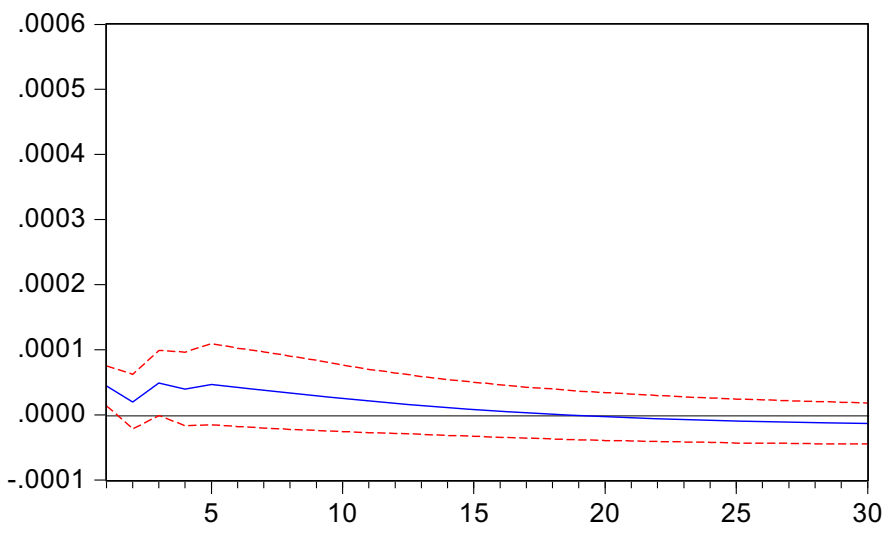

Response of FSI to oil prices

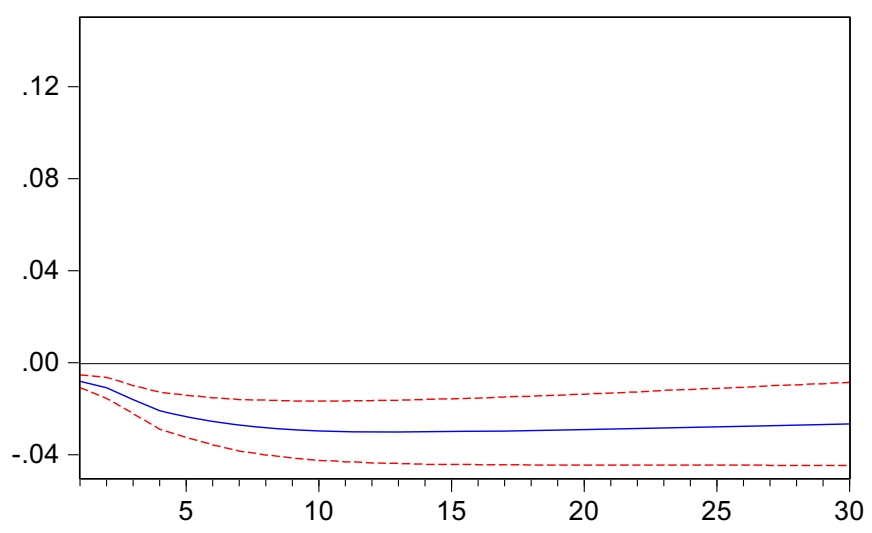

Response of oil prices volatility to FSI volatility

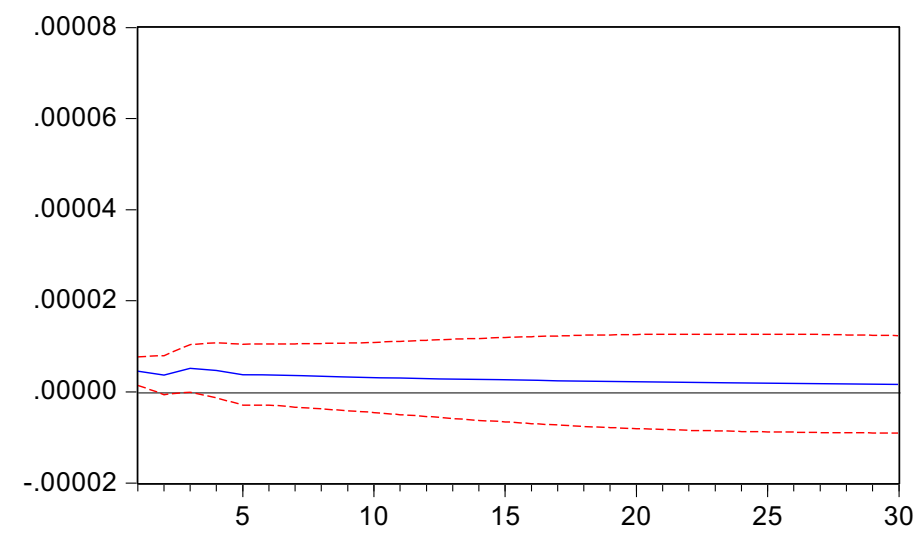

Response of oil prices to FSI

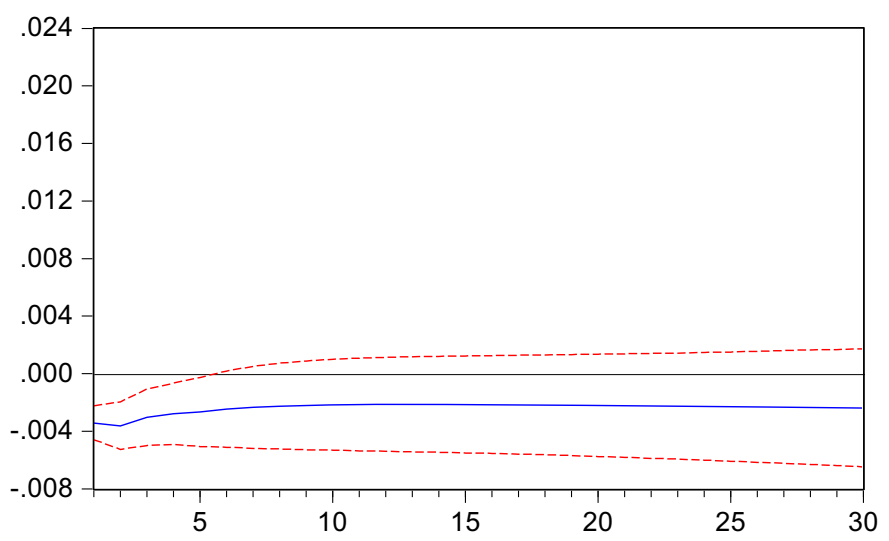

Fig. 5. Impulse-response functions for the post-crisis period.

prices and financial stress are dominated by persistent long-run volatility (Nazlioglu et al., 2013).

The volatility spillover analysis provides interesting implications regarding how energy and financial markets respond each other to risk perceptions. The existence of volatility spillover from energy to financial markets implies that investors transmit their high risk perceptions from oil markets to financial markets. This implies that information from oil markets improves the volatility forecasts in CFSI. Hence, investors must take energy markets into account in their financial portfolio formation decisions and in developing their hedging strategies. Another implication can be derived from the finding that volatility in oil markets leads volatility in financial stress. Volatility in oil returns is more sensitive to outside shocks than changes in financial stress index. The neutrality between energy and financial markets can be attributed to the reason that investors generally keep their positions to avoid negative effects of manipulative attacks which arise from very high uncertainty in the financial markets.

Lack of Granger causality in levels implies that oil market and financial stress did not share an equilibrium path before the crisis. Hence, in the pre-crisis period, investors could view financial markets as alternative investment areas to oil markets for portfolio diversification purposes. This opportunity however, seems to have disappeared due to the crisis. The causality-in-variance and the causality-in-mean analyses clearly show that causal linkages between oil price and financial stress are rather rich and complicated. Furthermore, the oil market has become more relevant for financial stress after the crisis. This result is interestingly similar to Turhan et al. (2013) results, who investigate the link between oil price and 13 emerging market exchange rates. Using similar subperiods they report no mean spillover between oil and exchange rates in the pre-crisis period. However, after the crisis in 10 out of 13 markets they find oil prices leading exchange rates. In a sense, the TY results in our study seem to be generalizing the relevance of oil prices for exchange rate markets to all financial sectors after the crisis. The 2008 crisis seem to have severed the link between financial asset and oil markets. This confirms Büyükssahin et al. (2010) and Büyükşahin and Robe (2014) who find decreased correlations between oil and equity markets during financial turmoils. This is probably due to chaotic response of investors in both markets in the face of increased uncertainty. As market players form expectations and revise their positions, the relationship between FSI and oil price seem to settle to a new equilibrium, which is completely different from the one before the crisis. Policy makers should see oil price hikes as a highly likely signal for increased financial stress level. On the other hand, increased volatility in FSI should be viewed as a possible source of increased volatility in oil markets.

Our findings suggest that the behavior of energy and financial markets with respect to price dynamics and risk perceptions may not share similar patterns and both are necessary to get the entire picture. The picture we paint has different implications for investors and speculators. Investors engage in hedging strategies to decrease their exposure to risk. Therefore, volatility dynamics in the oil market and its relationship to financial stress are important for investors in both oil and financial asset markets. Speculators trade with the objective of achieving profits through taking advantage of a price differences between two markets (i.e., 
arbitrage). Since price level relations play a crucial role in arbitrage, the daily mean spillover may provide insightful information for speculators. The existence and direction of mean spillover between oil price and financial stress index is also essential to investors in both types of markets from a long run portfolio optimization perspective.

\section{Conclusions}

\subsection{Summary and implications}

This study examines volatility transmissions between world oil prices and financial stress for the pre-crisis, the in-crisis (2008), the post-crisis periods by utilizing the volatility spillover test by Hafner and Herwartz (2006). The paper also investigates the dynamic transmission mechanism by conducting the Toda and Yamamoto (1995) causality test to decipher long-run causal linkages between the two variables of interest. Finally, we also derive the generalized impulse response functions to compare how energy and financial markets respond to short-run temporary shocks.

Our results indicate significant spillover between the energy and financial markets, both in terms of volatility and mean estimates. This has important implications, as the result suggests that, besides the direct effect of oil shocks and financial stress on the economy, there are likely to be secondary (indirect) effects on the economy through the energy and financial markets affecting each other following a shock in one market. This, in turn, implies that the effect of oil and financial markets are likely to be more prolonged and persistent on the economy, and could lead to underestimation of the effects if the policy maker does not account for the possible linkage between the energy and financial markets. From an econometric modeling perspective, this implies that models analyzing the effects of financial market shocks and oil shocks on the economy separately are likely to be flawed, and needs to simultaneously incorporate both these variables in the model-an interesting area of future research. From a policy perspective this is pivotal, since the required optimal reaction of the policy maker should be stronger, following an oil or financial shock, accounting for the interaction between these two markets, relative to the scenario when these two markets are considered to be segmented and not modeled within the same econometric framework

\subsection{Limitations and future directions}

In this study, we only concentrate on bivariate analysis between oil prices and financial stress. The nature of linkages between energy and financial markets provides room to account for other variables which affect the behavior of those markets. Future studies can therefore consider the risk transfers within multivariate frameworks. Nevertheless, we assume herein that the impact of a positive shock is similar to that of a negative shock, and thereby we do not consider the asymmetric causal linkages for the positive and negative shocks. The asymmetry can be considered as the natural behavior of financial markets due to the fact that global investors react more strongly to negative than to positive shocks. Therefore, asymmetric causal linkage between energy and financial markets is an open question for the future research. Furthermore, our results also suggest that the relationship between financial stress and oil prices can change through time which provides an opportunity for regime-switching models to examine.

\section{Acknowledgments}

We would like to thank the Guest Editor Duc Khuong Nguyen, the Editor Lorna A. Greening, and two anonymous referees for valuable comments and suggestions. We also would like to thank the participants of the 2nd International Symposium on Energy and Finance Issues (ISEFI-2014). Saban Nazlioglu gratefully acknowledge the financial support for the previous version of this paper by The Unit of Pamukkale University Scientific Research Projects and Funds under research grant number 1963 to be presented at the ISEFI-2014.

\section{References}

Aloui, C., Nguyen, D.K., Njeh, H., 2012. Assessing the impacts of oil price fluctuations on stock returns in emerging markets. Econ. Model. 29, 2686-2695. Awokuse,

T.O., 2003. Is the export-led growth hypothesis valid for Canada? Can. J. Econ. 36 (1), 126-136.

Balakrishnan, R., Danninger, S., Elekdag, S., Tytell, R., 2009. The Transmission of Financial Stress from Advanced to Emerging Economies. IMF Working Paper.

Balke, N.S., Brown, S.P.A., Yücel, M.K., 2002. Oil price shocks and the US economy: where does the asymmetry originate? Energy J. 23, 27-52.

Bollerslev, T., 1986. Generalized autoregressive conditional heteroskedasticity.

J. Econ. 31, 307-327.

Bollerslev, T., Chou, R.Y., Korner, K.F., 1992. ARCH modelling in finance: a review of the theory and empirical evidence. J. Econ. 52, 5-59.

Büyükşahin, B., Haigh, M.S., Robe, M.A., 2010. Commodities and equities: ever a "Market of One"? J. Altern. Invest. 12, 76-95.

Büyükşahin, B., Harris, J.H., 2011. Do speculators drive crude oil futures prices? Energy J. 32, 167-202.

Büyükșahin, B., Robe, M.A., 2014. Speculators, commodities and cross-market linkages. J. Int. Money Financ. 42, 38-70.

Cardarelli, R., Elekdag, S., Lall, S., 2011. Financial stress and economic contractions.

J. Financ. Stab. 7, 78-97.

Cevik, E.I., Dibooglu, S., Kenc, T., 2013. Measuring financial stress in Turkey. J. Policy Model. 35, 370-383.

Chau, F., Deesomsak, R., 2014. Does linkage fuel the fire? The transmission of financial stress across the markets. Int. Rev. Financ. Anal. 36, 57-70. http://dx.doi. $\operatorname{org} / 10.1016 / \mathrm{j}$. irfa.2014.02.005.

Chen, W., Hamori, S., Kinkyo, T., 2014. Macroeconomic impacts of oil prices and underlying financial shocks. J. Int. Financ. Mark. Inst. Money 29, 1-12.

Cheung, Y.W., Ng, L.K., 1996. A causality in variance test and its application to financial market prices. J. Econ. 72 (1-2), 33-48.

Cunado, J., de Gracia, F.P., 2003. Do oil price shocks matter? evidence for some European countries. Q. Rev. Econ. Financ. 45, 65-83.

Cunado, J., de Gracia, F.P., 2005. Oil prices, economic activity, and inflation: evidence for some Asian countries. Energy Econ. 25, 137-154.

Cunado, J., de Gracia, F.P., 2014. Oil price shocks and stock market returns: evidence for some European countries. Energy Econ. 42, 365-377.

Dickey, D.A., Fuller, W.A., 1979. Distribution of the estimators for autoregressive time series with a unit root. J. Am. Stat. Soc. 75, 427-431.

Dovern, J., van Roye, B., 2014. International transmission and business cycle effects of financial stress. J. Financ. Stab. 13, 1-17.http://dx.doi.org/10.1016/j. jfs.2014.02.006.

Elliott, G., Rothenberg, T.J., Stock, J.H., 1996. Efficient tests for an autoregressive unit root. Econometrica 64, 813-836.

Engle, R.F., 1982. Autoregressive conditional heteroskedasticity with estimates of the variance of United Kingdom inflation. Econometrica 50, 987-1007. Granger, C.W.J., 1996. Investigating causal relations by econometric models and cross-spectral methods. Econometrica 37, 424-438.

Gupta, R., Modise, M.P., 2013. Does the source of oil price shocks matter for South African stock returns? A structural VAR approach. Energy Econ. 40, 825-831.

Hafner, C.M., Herwartz, H., 2006. A Lagrange multiplier test for causality in variance. Econ. Lett. 93 (1), 137-141.

Hamilton, J., 2011. Nonlinearities and the macroeconomic effects of oil prices. Macroecon. Dyn. 15, 364-378.

Hong, Y., 2001. A test for volatility spillover with application to exchange rates.

J. Econ. 103, 183-224.

Illing, M., Liu, Y., 2006. Measuring financial stress in a developed country: an application to Canada. J. Financ. Stab. 2, 243-265.

Jimenez-Rodriguez, R., Sanchez, M., 2005. Oil price Shocks and Real GDP Growth: Empirical Evidence for Some OECD Countries. Appl. Econ. 37, 201-228.

Jouini, J., 2013. Return and volatility interaction between oil prices and stock markets in Saudi Arabia. J. Policy Model. 35, 1124-1144

Kilian, L., 2008. The economic effects of energy price shocks. J. Econ. Lit. 46, 871-909.

Killian, L., 2009. Not all oil price shocks are alike: disentangling demand and supply shocks in the crude oil market. Am. Econ. Rev. 99, 216-240.

Killian, L., Murphy, D.P., 2014. The role of inventories and speculative trading in the global market for oil. J. Appl. Econ. 29, 454-478. 
Koop, G., Pesaran, M.H., Potter, S.M., 1996. Impulse response analysis in nonlinear multivariate models. J. Econ. 74, 119-147.

Kwiatkowski, D., Phillips, P.C.B., Schmidt, P., Shin, Y., 1992. Testing the null hypothesis of stationary against the alternative of a unit root. J. Econ. 54, 159-178.

Mallick, S.K., Sousa, R.M., 2013. The real effects of financial stress in the Eurozone. Int. Rev. Financ. Anal. 30, 1-17.

Mollick, A.V., Assefa, T.A., 2013. US stock returns and oil prices: the tale from daily data and the 2008-2009 financial crisis. Energy Econ. 36, 1-18.

Morana, C., 2013. Oil price dynamics, macro-finance interactions and the role of financial speculation. J. Bank. Financ. 37, 206-226.

Narayan, P.K., Pop, S., 2010. A new unit root test with two structural breaks in level and slope at unknown time. J. Appl. Stat. 37 (9), 1425-1438.

Nazlioglu, S., Soytas, U., 2011. World oil prices and agricultural commodity prices: evidence from an emerging ,market. Energy Econ. 33, 488-496.

Nazlioglu, S., Erdem, C., Soytas, U., 2013. Volatility spillover between oil and agrieultural commodity markets. Energy Econ. 36 (1), 658-665.
Park, J., Ratti, R.A., 2008. Oil price shocks and the stock markets in the US and 13 European countries. Energy Econ. 30, 2587-2608.

Park, C.-Y., Mercado, Jr, R.V., 2014. Determinants of financial stress in emerging market economies. J. Bank. Financ. 45, 199-224.

Pesaran, M.H., Shin, Y., 1998. Generalized impulse response analysis in linear multivariate models. Econ. Lett. 58, 17-29.

Rafiq, J., Salim, R., Bloch, H., 2009. Impact of crude oil price volatility on economic activities: an empirical investigation in the Thai economy. Resour. Policy 34 121-132.

Soytas, U., Oran, A., 2011. Volatility spillover from world oil spot markets to aggregate and electricity stock index returns in Turkey. Appl. Energy 88, 354-360.

Toda, H.Y., Yamamoto, T., 1995. Statistical inference in vector autoregression with possibly integrated processes. J. Econ. 66, 225-250.

Turhan, I., Hacihasanoglu, E., Soytas, U., 2013. Oil prices and emerging market exchange rates. Emerg. Mark. Financ. Trade 49, 21-36. 